\title{
Experiência com parceiros mais velhos e desenvolvimento de crianças na creche
}

\author{
Cássia Cristina Barreto Santos ${ }^{1}$
}

cassiabarreto2004@ig.com.br

\author{
Ana Rosa Costa Picanço Moreira ${ }^{2}$ \\ anarosamaio@uol.com.br \\ Vera Maria Ramos de Vasconcellos ${ }^{3}$ \\ vasconcellos.vera@gmail.com
}

\begin{abstract}
Resumo
Neste artigo analisamos as ações e narrativas de crianças numa situação de brincadeira livre, bem como o papel do educador em favorecer ou não a criatividade das mesmas no contexto da dramatização. Participaram do estudo uma educadora, quatro crianças de três anos de idade e quatro crianças de quatro anos, numa creche pública. Para realizar a atividade de dramatização, a educadora utilizou um saco com quatro fantoches (de mais ou menos um metro cada um deles): uma bruxa, uma menina, um menino e um bicho diferente, sem gênero definido ("Bicho Cárie"). Ela solicitou às crianças que fizessem dramatizações utilizando os fantoches. Nosso objetivo foi investigar em que medida as crianças mais novas eram capazes de identificar e
\end{abstract}

1 Professora na educação infantil da rede de ensino municipal do Rio de Janeiro. Mestranda em Educação da UERJ. Membro do grupo de pesquisa Infância e Saber.

2 Professora adjunta da UFJF, mestre em Psicologia Social pela Universidade Gama Filho e doutora em Educação pela UERJ. Membro do Núcleo de Estudos da Infância: Pesquisa e Extensão e coordenadora adjunta do Núcleo de Pesquisa Linguagem, Educação, Formação de Professores e Infância (LEFoPI/UFJF).

3 Professora titular da UERJ/PROPED/FE. Mestre, doutora e pós-doutora em Psicologia. Coordena o Núcleo de Estudos da Infância: Pesquisa \& Extensão/UERJ.

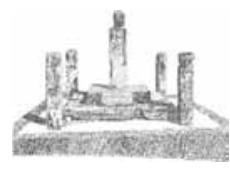

115

Ano 13 - n. 16 - dezembro 2010 - p. 115-146 
assumir o ponto de vista das mais velhas. Os episódios interativos foram gravados em vídeo e, posteriormente, analisados. Os resultados indicaram que, algumas vezes, o educador tem dificuldade de se engajar nas brincadeiras e aceitar modos de lidar com a situação imaginária diferentes dos planejados. Por outro lado, ele se constitui num mediador das interações sociais e produções criativas das crianças.

Palavras-chave: creche; faz de conta; zona de desenvolvimento proximal.

\section{Introdução}

Vivemos emumaépoca derápidas mudanças sociais etecnológicas, que nos fazem repensar vários aspectos da educação infantil. O fazer pedagógico, em especial, tem passado por reformulações conceituais e metodológicas relacionadas, principalmente, à entrada de crianças cada vez mais novas em unidades educacionais, como a creche e a préescola. Por sua vez, isso tem provocado algumas inquietações sobre os processos de desenvolvimento e aprendizagem e as modalidades de ações docentes possíveis em relação à criança pequena.

Desde muito cedo, a criança tem demonstrado capacidade de interagir com o meio, transformando-o e transformando-se, sendo protagonista - ator e autor - de seu próprio processo de desenvolvimento e aprendizagem. A partir das reflexões realizadas com pesquisadores da Educação e da Psicologia, no Núcleo de Educação da Infância: Pesquisa e Extensão da Universidade do Estado do Rio de Janeiro (NEI:PE/UERJ), alguns conceitos fundamentais para o cotidiano do trabalho docente na educação infantil foram ressignificados. Essas reflexões apontaram para a necessidade de se criar novas metodologias de educação para e com a infância que superassem as visões e as concepções tradicionais de criança, seu desenvolvimento e sua aprendizagem ao integrar o cuidado e a educação.

Com base nos estudos e pesquisas realizados pelo NEI:PE/ 
UERJ, nos últimos sete anos - Aquino (2008 e 2010); Vasconcellos, Aquino e Dias (2008); Vasconcellos e Sarmento (2007); Vasconcellos e Aquino (2005); Moreira e Vasconcellos (2008) -, e na discussão das teorias socioculturais, propomos uma prática mais crítica e coerente com a realidade de cada agrupamento de crianças, no sentido de se valorizar suas competências e necessidades.

O estudo foi conduzido numa creche institucional para filhos de funcionários públicos do município do Rio de Janeiro ${ }^{4}$, que tem por princípio oportunizar o desenvolvimento da autonomia das crianças por meio de uma proposta pedagógica embasada na perspectiva sócio-histórica-cultural. A instituição procura oferecer um ambiente educacional coletivo, no qual as crianças possam crescer e se desenvolver de forma saudável, com espaço físico seguro, além de propiciar brincadeiras livres com outros colegas e a construção do conhecimento com a mediação de adultos experientes e atentos. Para atingir esse objetivo, investe-se em uma proposta pedagógica que contemple a capacitação dos profissionais em serviço, e os ambientes são organizados de acordo com as necessidades das crianças. Além disso, há a valorização da presença de familiares no ambiente da instituição.

Analisamos uma situação real, advinda da necessidade de dar visibilidade e valorizar as interações de crianças pertencentes à turma de maternal II, composta por 11 meninos e sete meninas. O objetivo central foi investigar como as interações realizadas por um grupo focal de oito crianças (quatro delas com três anos incompletos e quatro com idade de quatro anos) resultaram no desenvolvimento de todas elas. A proposta pedagógica que aqui será apresentada destaca os conteúdos criativos e argumentativos do grupo focal numa brincadeira de faz de conta. Nesse sentido, buscamos compreender como esses pequenos atores sociais interpretam, reproduzem e/ou ressignificam as regras sociais presentes em seu dia-a-dia.

A dinâmica original dos agrupamentos com turmas

4 A creche institucional em estudo está localizada no bairro Cidade Nova, na cidade do Rio de Janeiro, e recebe, em média, cento e cinquenta e cinco crianças, de zero a quatro anos, das $7 \mathrm{~h}$ às $17 \mathrm{~h}$, de segunda-feira a sexta-feira. 
heterogêneas foi proposta pela direção da creche, tendo como objetivo potencializar o desenvolvimento das crianças. Essa modalidade acabou por ser mostrar como uma proposta enriquecedora e fortalecedora do objetivo central deste trabalho, qual seja, a de perceber a criança mais velha como parceiro privilegiado de desenvolvimento da mais nova.

Baseadas nas proposições de Lev Vygotsky (1896-1934) e colaboradores, referentes ao jogo de faz de conta e à importância da relação com parceiros mais velhos, apresentamos, inicialmente, algumas contribuições sobre o "ato criativo" nas interações sociais de crianças e na constituição delas como sujeitos sociais. Também enfatizamos a necessidade de se relacionarem não apenas com seus pares da mesma faixa etária, mas que tenham oportunidade de interagir com parceiros mais experientes, sejam eles crianças ou adultos, pois isso é compreendido como um convite à aprendizagem.

Em seguida, apresentamos as descrições e análises de episódios interativos que foram documentados mediante videogravação e registros escritos. A metodologia escolhida para análise das videogravações foi a microgenética ${ }^{5}$, já que por meio dela é possível obter detalhes de episódios de interação criança-criança sem negar a participação do adulto. As experiências em pequenos grupos, como as situações de dramatização, compuseram as análises. Por fim, mostramos uma visão prospectiva do desenvolvimento infantil a partir dos dados obtidos e das análises realizadas.

Esperamos que este artigo possa contribuir para a formação do profissional de educação infantil, pensando o educador como aquele que propicia espaços de criação e situações de brincadeira que valorizem os processos imaginativos, a dimensão simbólica e a construção do conhecimento da criança, que é protagonista. Acreditamos, assim, que seja possível repensar uma educação infantil que enfatize a dialética presente nos saberes e fazeres dos educadores e das crianças.

5 Análise microgenética é uma forma de construção de dados em que os sujeitos focais, as relações intersubjetivas e as condições sociais da situação produzem um relato minucioso dos acontecimentos a partir de uma matriz histórico-cultural. (GÓES, 2000a, p. 9-10). 


\section{Uma visão sócio-histórica e cultural de desenvolvimento}

Lev Vygotsky (1998a), um dos principais representantes da perspectiva sócio-histórica-cultural, apresenta o estudo do desenvolvimento humano como a compreensão da unidade dialética de duas linhas principais e distintas: a biológica e a cultural, que exercem influência mútua. $O$ autor defende que

nosso conceito de desenvolvimento implica a rejeição do ponto de vista comumente aceito de que o desenvolvimento cognitivo é resultado de uma acumulação gradual de mudanças isoladas. Acreditamos que o desenvolvimento da criança é um processo dialético complexo caracterizado pela periodicidade, desigualdade no desenvolvimento de diferentes funções, metamorfose ou transformação qualitativa de uma forma em outra, imbricamento de fatores internos e externos e processos adaptativos que superam os impedimentos que a criança encontra (VYGOTSKY, 1998a, p. 96-97).

A abordagem vygotskyana enfatiza que as características biológicas preparam a criança para agir no meio social e para modificá-lo, mas que essa ação termina por influenciar na construção de suas próprias características biológicas. Não é apenas a criança que se desenvolve e se modifica no processo de interação com o outro e com o meio. Ambos também se constituem, constroem-se e mudam a si mesmos. Nesse sentido, Vygotsky dá destaque ao papel da mediação no processo de aprendizagem e aquisição do conhecimento, atentando para o fato de que por meio dessa ação é que se possibilitará a aquisição dos valores culturais de determinada sociedade. Isso porque é com o outro (indivíduos e/ou objetos de conhecimento) que o sujeito estabelece relações e elabora seus processos cognitivos de conhecimento do mundo. $\mathrm{Ou}$ seja, a partir da mediação do e com o outro, as pessoas se apropriam e elaboram as formas de atividade prática e mental pertinentes à

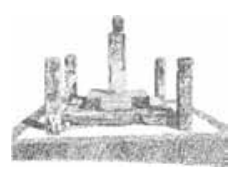


determinada cultura.

Vygotsky tece uma abordagem dos processos psicológicos entrelaçada às dimensões culturais, históricas e semióticas presentes na constituição do sujeito, destacando seu papel criativo. Por isso, define a atividade criadora ou criatividade como

[...] toda realização humana criadora de algo novo, quer se trate de reflexos de algum objeto do mundo exterior, quer de determinadas construções do cérebro ou do sentimento, que vivem ou se manifestam apenas no próprio ser humano (VYGOTSKY, 1998, p. 7).

A criatividade é uma característica que pertence ao homem, que é um ser social desde a sua origem, pois já nasce inserido em uma determinada cultura. Isso ocorre porque a criança, ao nascer, já apresenta certas estruturas internas (biológicas), que vão sendo modificadas nas interações com o ambiente. São essas estruturas que irão agir a partir das interpretações e dos significados que a criança atribui a suas expressões, gestos, posturas, sons, tornando-a, assim, participante ativa do mundo simbólico da cultura a que pertence.

Vygotsky (1998a) defende que o ser humano constrói seus conhecimentos e sua subjetividade ao estabelecer relações, que irão organizar e explicar o mundo que o circunda. Assim,

se considerarmos que a criação consiste, em seu verdadeiro sentido psicológico, em fazer algo novo, é fácil chegar à conclusão de que todos podemos criar em maior ou menor grau e que a criação é fato normal e permanente do desenvolvimento infantil (VYGOTSKY, 1998a, p. 7).

A ação manifesta-se na criança, nas interações (ações partilhadas) que estabelece com o mundo, com o meio, que é simbólico e histórico, portanto, ideológico, em situações definidas pelo autor como zona de desenvolvimento proximal. Nela, é privilegiada a interação com parceiros mais experientes como forma ativa da criança se relacionar com o mundo, sendo protagonista do seu próprio processo de aprendizado e desenvolvimento. Segundo o 
autor (1988a), a zona de desenvolvimento proximal é caracterizada por certa tensão entre o nível de desenvolvimento real e o nível de desenvolvimento potencial, sendo definida como

[...] a distância entre o nível de desenvolvimento real, que se costuma determinar através da solução independente de problemas, e o nível de desenvolvimento potencial, determinado através da solução de problemas sob a orientação de um adulto ou em colaboração com companheiros mais capazes (VYGOTSKY, 1998a, p. 112).

Dessa forma, o desenvolvimento ocorre em dois níveis: (1) o real, referente ao desenvolvimento já alcançado e caracterizado pela independência nas ações; por exemplo, tudo que a criança realiza de forma autônoma e (2) o potencial, que se relaciona às competências em via de serem conquistadas - aquilo que o sujeito ainda não é capaz de realizar de forma independente e, por isso, necessita da colaboração do outro.

O conceito de zona de desenvolvimento proximal indica a distância entre os dois níveis de desenvolvimento humano - o real e o potencial. Mas, para transformar o que é potencial em real, faz-se necessária a instauração de um espaço de ações partilhadas, pois na interação com o outro se adquire a capacidade de internalizar conceitos, de organizar o real e de regular internamente as ações. Os fenômenos de transição do desenvolvimento perpassam por todo território intermediário entre o externo e o interno, assim como reintegra um território comum: o da cultura.

No contexto da creche, o educador pode ter papel privilegiado de mediador, facilitando a criação de zonas de desenvolvimento proximal. É ele quem promove situações de aprendizagem e um ambiente de brincadeira no qual a outra criança atua como facilitadora da passagem de um nível atual de desenvolvimento para o potencial. Nesse sentido, Vasconcellos entende que

a zona de desenvolvimento proximal ajuda o educador a ficar atento não só para o que a criança faz, mas para o que ela poderá 
vir a fazer, num momento próximo-futuro, pensando o desenvolvimento infantil de forma prospectiva (VASCONCELLOS, 1998, p. 53).

Assim, as interações que o sujeito estabelece com o outro criam as zonas de desenvolvimento proximal, e a vivência da criança com parceiros mais experientes a leva a perceber o mundo de forma simbólica, tal qual os mais experientes o representam. A criança se comporta ativamente, recriando a sua realidade de forma própria. Hoje, a zona de desenvolvimento proximal será o nível de desenvolvimento real amanhã. Ou seja, aquilo "que uma criança pode fazer com assistência hoje, ela será capaz de fazer sozinha amanhã" (VYGOTSKY, 1998a, p. 113).

$\mathrm{Na}$ riqueza de sua vivência, portanto, a criança parte da experiência acumulada para na repetição das ações, nas palavras ouvidas, no compartilhar histórias, nas expressões, na forma de ver o mundo, em um processo de combinar experiências antigas com as novas, constituir o alicerce da criação. Quanto mais rica é a experiência, maior será a sua imaginação, já que a primeira alimenta a fantasia e esta, por sua vez, participa da ampliação da experiência.

\section{A importância das ações imitativas}

As crianças podem imitar uma variedade de ações, sendo capazes de fazer coisas que vão muito além dos limites de suas próprias habilidades durante suas interações com o outro. Para Vygotsky (1998a, p. 96), “o aprendizado humano pressupõe uma natureza social específica e é um processo através do qual as crianças penetram na vida intelectual daqueles que a cercam". Porém, nas práticas correntes na educação infantil, o "ato imitativo", que parece ter pouco significado em si mesmo, não é valorizado adequadamente pelos educadores, apesar de ter fundamental importância, na medida em que demanda uma alteração positiva quando valorizado na inter-relação do aprendizado e do desenvolvimento das crianças. 
Cabe-nos destacar que a interação com o parceiro mais experiente potencializa as ações imitativas, fornecendo base para o processo de desenvolvimento da criança. Podemos perceber que o aprendizado possibilitado por essas ações cria a zona de desenvolvimento proximal e desperta, por sua vez, vários processos internos de desenvolvimento que são capazes de operar somente quando a criança interage com outras pessoas de seu ambiente e/ou em cooperação com companheiros mais experientes. Assim, para Vygotsky (1998a, p. 118), “o aprendizado é um aspecto necessário e universal do processo de desenvolvimento das funções psicológicas culturalmente organizadas e especificamente humanas".

Logo, o que torna significativo o trabalho desenvolvido com crianças na educação infantil é acompanhar, potencializar e criar momentos de interação com o outro, promovendo situações de aprendizagem que se transformam em zonas de desenvolvimento proximal. Isso possibilita criar situações nas quais as crianças consigam realizar ações entre elas mesmas, visto que isoladas ainda não conseguiriam. Mais tarde, irão resolvê-las de forma independente, o que caracteriza o nível de desenvolvimento real:

Os processos de desenvolvimento não coincidem com os processos de aprendizado. Ou melhor, o processo de desenvolvimento progride de forma mais lenta e atrás do processo de aprendizado; desta sequenciação resultam, então, as Zonas de Desenvolvimento Proximal (VYGOTSKY, 1998a, p. 118).

São essas interações que o indivíduo estabelece com o meio e, em especial, com o outro, que são essenciais para a constituição do pensamento e da personalidade. Na educação infantil, a criança se socializa de forma planejada, tendo contato com outros indivíduos fora de seu convívio familiar e aprendendo regras sociais comuns a seu meio. É o momento em que a criança passa, efetivamente, a se confrontar com a "cultura" de seu meio social.

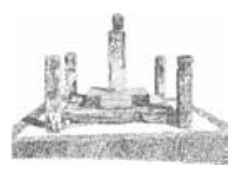




\section{Análise microgenética de episódios interativos na brincadeira de faz de conta}

Para realizar a atividade de dramatização, a educadora utilizou um saco de pano bege ("saco surpresa"), com quatro fantoches (de mais ou menos um metro cada um deles): uma bruxa, uma menina, um menino e um bicho diferente, sem gênero definido ("Bicho Cárie"). Ela solicitou às crianças que produzissem uma dramatização a partir do material fornecido ${ }^{6}$. A análise dos episódios interativos (vídeos gravados) resultou na identificação de três eixos: (1) - Como a educadora inicia as atividades; (2) - a nomeação dos fantoches; (3) - a composição da história.

Cada um dos aspectos citados contém recortes dos episódios, seguidos de análises das produções criativas das crianças e também da atuação da educadora nas situações de faz de conta. $\mathrm{O}$ foco de análise se deu na direção da ação do parceiro mais velho no desenvolvimento da criança mais nova.

\section{Transcrição e análise dos episódios}

\section{$1^{0}$ EPISÓDIO: Como a educadora conduz a atividade?}

A educadora senta-se com as oito crianças em roda e posiciona o "saco surpresa" próximo a ela.

Educadora: - "Vamos ver a novidade que tem nesse saco? Vamos?

O que será que é? O que vocês acham que é?"

RUY (4 anos): - "Dinossauro".

Educadora: - "Será que é alguma coisa de dinossauro?"

RUY: - "Eu acho que é uma montanha que tem o T-Rex".

Educadora: - "Será que é uma montanha que tem o T-Rex? (risos).

6 Esta modalidade de análise segue a desenvolvida por Cynthia de Souza Paiva Nascimento na dissertação de mestrado intitulada "Criatividade e Brincadeira de Faz de Conta nas Concepções de Professores de Educação Infantil" (Mestrado em Educação) - Universidade Federal Fluminense, 2008.

7 T-Rex, abreviação de Tiranossauro Rex, dinossauro que a turma estava conhecendo nas atividades do projeto do mês corrente. 
Vamos ver... não sei". (Até esse momento o saco está nas mãos da educadora). Eu vou abrir o saco e vocês vão ver".

RUY: - "É um saco mágico?" (Pergunta, enquanto a educadora abre o saco).

Educadora: - "Não sei, vem aqui ver".

As crianças se levantam e olham dentro do saco.

MÁRIO (3 anos - $1^{\mathrm{a}}$ criança focal): Retira um fantoche e diz: - "É o lobo." (Em relação ao "Bicho Cárie”).

M. ELY (4 anos): Retira o fantoche do menino e da menina. -"Essa aqui é a boneca". (Sai correndo da roda).

FAUSTO (4 anos): - "Ela, M. Ely, está com dois". (Sai da roda em direção a M. Ely).

M. ELY: - “Não! Não!”

FAUSTO: - "Oh tia, eu não tenho nenhum".

KARLA (4 anos): - "É para fazer o que, tia? Isso aqui é o quê?" (Com o fantoche da bruxa na mão).

Educadora: - "O que que é isso?"

KARLA e FAUSTO: - “Uma Bruxa!”

M. ELY: - "Eu quero a Bruxa..."

Educadora: - "Olha, só quem ficou sem..."

KARLA: - "Maya ficou sem".

MAYA (3 anos - $2^{\text {a }}$ criança focal): - "Tia , eu tô sem..."

Educadora: - "Espera, daqui a pouco você vai pegar emprestado, tá?" Karla brinca com o fantoche da Bruxa, balançando-o e diz: - "Eu sou uma Bruxa, eu sou uma Bruxa".

Karla continua brincando com o fantoche de Bruxa e começa a balançá-lo no rosto de Gina ( 3 anos - $3^{\text {a }}$ criança focal). Gina, de início, tampa o rosto, como se estivesse com medo, depois se cansa e empurra o fantoche da Bruxa.

MÁRIO: - "Tia, tá apertado". (Mostra-lhe a mão com o fantoche que nomeou de "Lobo").

Educadora: - "Tá apertado? Espera aí". (Ajuda a encaixá-lo corretamente).

Yana (3 anos - $4^{\mathrm{a}}$ criança focal) segura e brinca com o fantoche de menina (nomeado por M. Ely de "Boneca"), mas não o encaixa 
na mão.

KARLA: - "Olha a Bruxa, tia!"

YANA: - "Tia, olha aqui". (Mostra o fantoche da menina "Boneca").

Educadora: - "Prestem atenção, crianças que pegaram bonequinho (fantoche). Vamos inventar uma história para quem ficou sem bonequinho?"

FAUSTO: - "Esse é o Júlio". 8 (Balança o fantoche do menino).

Yana observa Fausto balançando o fantoche do menino ("Júlio") e balança o da menina na direção dele, propondo que os fantoches se comuniquem. Fausto não percebe o convite de Yana.

\section{Discussão do $1^{\circ}$ episódio}

Arranjo espacial: as crianças estavam sentadas ao chão, formando um círculo (rodinha). A educadora colocou o "saco surpresa" próximo a ela, desamarrou-o e as convidou a retirarem os fantoches. Liberdade de expressão: a educadora, antes de abrir o "saco surpresa", aguçou a curiosidade das crianças indagando sobre o que havia ali. Ruy soltou a imaginação e disse que era uma montanha com o Tiranossauro Rex. A educadora incentivou a imaginação e as falas das crianças.

Nomeação dos personagens: Mário ( $1^{\mathrm{a}}$ criança focal) retirou o fantoche do "Bicho Cárie" e o nomeou de "Lobo". M. Ely retirou o fantoche do menino e da menina e a nomeou de "Boneca". Karla mostrou o fantoche da "Bruxa" para a educadora perguntandolhe do que se tratava, e a educadora lhe retornou a pergunta. Karla e Fausto a nomearam de "Bruxa" (nomeação conjunta do personagem). Após a educadora propor a composição de uma história, Fausto nomeou o fantoche do "menino" de "Júlio".

Ações interativas: Karla brincou com o fantoche da "Bruxa", balançando e dizendo: "Eu sou uma Bruxa". Também o mostrou para Gina que, no início, participava tampando o rosto e demonstrando medo. Logo depois, entrou na brincadeira e

80 fantoche, provavelmente, recebeu este nome por ter semelhanças com o boneco Júlio do desenho animado "Cocoricó". 
empurrou o fantoche (interação através do imaginário). Yana segurou-o, mas não conseguiu encaixar o fantoche da menina na mão e observou que Karla estava brincando com a "Bruxa". Yana mostrou o que a menina estava fazendo, dizendo: "Tia, olha aqui". Depois, Yana observou Fausto brincando com o fantoche do menino "Júlio" e balançou o da menina como se estivesse propondo que os fantoches se comunicassem (interação entre fantoches). Inicialmente apareceram seis propostas criativas (nomeação de personagens e interação com brincadeiras), porém, até aqui, as crianças focais (menores) ainda se dirigiram de modo preferencial à educadora.

Negociação: M. Ely retirou dois fantoches do "saco surpresa" e saiu da roda correndo. Fausto saiu atrás dela e tentou pegá-los. M. Ely lhe disse: - "Não! Não!". Fausto reclamou com a educadora: - “Tia, eu não tenho nenhum". Mário (criança focal) disse também ter ficado sem fantoche, e a educadora lhe respondeu: - "Espere um pouco que logo vai receber emprestado".

KARLA: - "Tia, a Maya ficou sem".

MAYA: - "Tia, estou sem".

Educadora: "Espera, daqui a pouco você vai pegar emprestado, tá?" Nesse episódio, há duas disputas (negociações) pelos fantoches. Os conflitos surgem e a educadora tenta mediá-los ao pedir às crianças que esperem um pouco para iniciar a troca de fantoches. Karla, criança mais velha, vem em defesa da menor (Maya), dizendo à educadora que a colega está sem fantoche.

\section{$2^{\circ}$ EPISÓDIO: Tentativa de composição da história}

Educadora: - "Júlio! A história do Júlio. Então vamos fazer o seguinte: Karla, Fausto e Mário podem ficar atrás do teatrinho e da Yana. A gente vai assistir ao teatrinho, tá?"

MAYA: - "Eu também quero".

Educadora: - "A gente vai assistir ao teatrinho, tá?"

Todos se levantam e vão até o teatrinho. Os que estão sem fantoche se sentam para assistir e as crianças que os têm vão contar a história, como a educadora sugeriu.

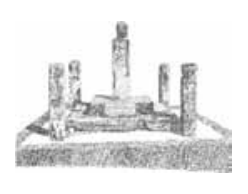

127 
MAYA: - "Eu quero, eu quero, quero".

Educadora: - “Senta, Maya, depois a gente vai trocar. Que história é essa?"

FAUSTO: "É a do Júlio".

Educadora: - "Ah! História do Júlio!"

KARLA: - "Eu sou uma Bruxa".

Como as crianças estão apertadas e pouco confortáveis abaixadas no teatrinho, elas se levantam e passam a contar a história de pé, em cima do teatrinho.

FAUSTO: - “Eu sou o Feitiço”. (Segurando o boneco antes chamado de "Júlio").

YANA: - "Eu sou o Feitiço". (Segurando o fantoche da menina sem encaixar na mão).

Educadora: - "Mário, quem é esse que está com você?"

MÁRIO: - "É o dinossauro".

Educadora: - "É um dinossauro, ah!" (Pede que eles fechem um pouco o teatro para não cair).

\section{Discussão do $2^{\circ}$ episódio}

Arranjo espacial: a educadora sugeriu às crianças que estavam com os fantoches que fossem para trás do teatrinho e àquelas sem o brinquedo, que ficassem na frente para serem os espectadores. As crianças ficaram de pé atrás do teatrinho, demonstrando familiaridade com a atividade de "teatro de fantoche", já que apareceu de forma encadeada uma proposta de história, com título, seguida de apresentação. Fausto disse: - "É a história do Júlio". Karla completou: - "Eu sou uma Bruxa" e Fausto: -"Eu sou o feitiço". Yana repetiu: - "Eu sou o Feitiço".

Liberdade de expressão: como Mário não se manifestou, a educadora buscou ajudá-lo a entrar na história, perguntando qual era o seu fantoche. Ele demorou a responder. Pensou e disse que era o "Dinossauro", segurando o "Bicho Cárie", que, antes, ele mesmo havia nomeado "Lobo". 
Mudança de personagens: nessa cena de faz de conta, houve o início de encadeamento de uma história e os nomes dos personagens foram modificados. $\mathrm{O}$ fantoche do menino, que primeiro foi nomeado "Júlio" e que era o nome da história que seria contada, na hora da apresentação, mudou para "Feitiço". O fantoche do "Bicho Cárie", antes nomeado "Lobo", também recebeu outro nome, "Dinossauro", dado pela mesma criança. Eles transgrediram a própria proposta, dando aos fantoches outras denominações, pois a educadora os incentivou a criação e a fantasia.

Ação criadora: Yana imitou o colega Fausto repetindo a expressão "Eu sou o Feitiço" independentemente de o fantoche que estava com ela ser uma boneca. Essa ação criadora, via imitação, fez com que ela participasse da brincadeira.

\section{$3^{\circ}$ EPISÓDIO: Negociação dos fantoches e nova identificação dos personagens}

FAUSTO: - "Mário, vamos trocar? Eu sou um Feitiço". (Segurando o boneco antes nomeado "Júlio"). O menino Mário (focal) balança a cabeça, dizendo que sim e fica com o boneco "Feitiço". YANA: - "Vamos trocar Maya, vamos trocar?" (E pega a "Bruxa"). Maya pega o fantoche da menina e tenta encaixar na mão. Mário, com o boneco do "Feitiço", pede à colega Yana para trocar pela "Bruxa", mas Yana nega. Há na primeira díade (Mário e Fausto) uma negociação bem-sucedida. Já Yana, imitando Fausto, propõe a Maya uma troca de fantoches, o que não é aceito pela menina. MÁRIO: - "Sim!"

YANA: - "Não!"

MÁRIO: - "Por que não?"

YANA: - "Porque não!"

MÁRIO: - "Sim!"

MÁRIO: - "Tia, a Yana não quer trocar comigo".

Educadora: - "Yana... Daqui a pouco ela troca com você, Mário. Empresta esse um pouco para sua colega M. Ely; ela ainda não 
pegou nenhum fantoche".

Acatando a sugestão da educadora, Mário empresta o fantoche do menino ("Feitiço") para M. Ely, que foi para o teatrinho.

FAUSTO: - "Vamos trocar, M. Ely?" (Fausto está com o fantoche "Dinossauro", que já havia trocado com Mário).

M. Ely faz a troca. Fausto aparece no teatrinho e diz repentinamente: - "Oi!" (Balançando o boneco).

Educadora: - "Conta uma história para mim, M. Ely".

FAUSTO: - "Fica aí. Todo mundo fica aí". (Ele também estava no teatrinho).

FAUSTO: - "Oi, eu sou o Feitiço".

M. ELY: - "Oi, eu sou o Jacaré". (Com o fantoche, inicialmente, denominado "Dinossauro" por Mário).

Os dois balançam os fantoches e começam a cantar a música do jacaré. Yana para e fica apertando o nariz da "Bruxa" e abraçando o fantoche. Mário, que quer a "Bruxa", fica olhando Yana brincar com o fantoche. Gina, que é mais observadora do que participante, também se aproxima e fica olhando Yana com a "Bruxa".

Educadora: - "Yana, quem é essa?"

YANA: - "A Bruxa".

Educadora: - "Ela é má ou boa?"

YANA: - "Boa".

MAYA: - "Tia, ela é boa". (Mostra o fantoche da menina).

Educadora: - "Quem é essa?"

MAYA: - "A Bonequinha".

Educadora: - "Ela tem nome, Maya?" (A educadora não percebe que Bonequinha é o nome dado ao fantoche).

MAYA: - "Não".

Yana, que observa o diálogo, diz: - "Só tem nome da Bruxa".

Educadora: - "Como é?"

YANA: - "Obla Bruxa".

Educadora: - "Como?"

KARLA: - "Obla Bruxa".

Educadora: - "Obla Bruxa?" 
Yana balança a cabeça dizendo que sim. Karla, que brinca com o fantoche da menina ("Bonequinha"), mostra-o para a educadora, que lhe pergunta: - "Ela é filha da Bruxa?". Karla pensa, diz que sim e começa a balançar o fantoche da "Bonequinha" para Yana, que está com a "Obla Bruxa”. Yana corre de Karla, que vai atrás dela balançando o fantoche da menina e diz: - "Sou filha da Bruxa, filha da Bruxa" (com a voz modificada). Gina (mais observadora do que participante) fica de pé parada, observando a cena das crianças correndo. Karla corre pela sala com o fantoche da "Bonequinha" denominada "filha da Bruxa".

KARLA: - "Vem aqui, mãe". (Falando com Yana e a "Obla Bruxa”).

O menino Fausto observa, ri e corre também.

\section{Discussão do $3^{\circ}$ episódio}

Arranjo espacial: nesse episódio, as crianças ainda estavam atrás do teatrinho e iniciaram um processo de troca de fantoches. A proposta de uma criança mais velha (Fausto) foi acatada pela menor (Mário) e seguida e imitada por outra menor (Yana), sem resistência da mesma. Por causa da negociação, elas se dispersaram e saíram de trás do teatrinho. Seguiu-se a isso uma série de negociações monossilábicas que acabaram com um pedido de socorro à educadora, que atuou como mediadora, porém sem solucionar a polêmica. Em seguida à realização das trocas, M. Ely foi para o teatrinho e, logo depois, Fausto a acompanhou. Iniciaram um processo de contar histórias, que foi sugerido novamente pela educadora.

Negociação: Fausto iniciou a proposta de troca do fantoche "Feitiço" pelo "Dinossauro", o que ocorreu sem resistência de Mário. Em seguida, Yana também trocou harmoniosamente a "Boneca" com Maya, que estava com a "Bruxa". No momento em que Mário tentou trocar o fantoche "Feitiço" pela "Bruxa", que estava com Maya, não conseguiu e reclamou com a educadora. Nesse episódio, houve uma disputa/negociação pelo fantoche. A educadora, apesar de ter sido solicitada para resolver a situação, não interferiu. Pelo 
contrário, pediu à criança que aguardasse e seguisse negociando a troca de fantoches. Outras negociações ocorreram e mais trocas foram realizadas, harmoniosamente, entre as próprias crianças.

Real X imaginário: nessa cena, em vários momentos, novas denominações para os personagens foram propostas. Cada uma das crianças nomeou o seu fantoche de forma própria, ampliando as possibilidades e o imaginário. Por exemplo, Fausto nomeou o fantoche do menino de "Júlio", trocando depois por "Feitiço", de acordo com o contexto da história. Mário, inicialmente, nomeou o fantoche do "Bicho Cárie" "Lobo" e, depois, "Dinossauro". Já M. Ely renomeou-o "Jacaré". Yana ampliou o nome da "Bruxa" para "Obla Bruxa”, criando, intencionalmente, uma nova palavra (“Obla"). Maya renomeou a menina "Bonequinha", que antes fora nomeada por M. Ely “Boneca”.

Ação criadora: interessante observar que a educadora, buscando ampliar a possibilidade criativa, lançou os conceitos de bem e mal para uma das crianças focais (Yana). Ela perguntou se a "Bruxa" era boa ou má. Yana vinha, já há algum tempo, explorando o fantoche da Bruxa, que, inicialmente, a intrigava. Ela respondeu à pergunta da educadora dizendo ser boa a bruxa. Em seguida, renomeou-a de "Obla Bruxa”, provavelmente para amenizar seu suposto medo de bruxas. Karla ampliou a produção coletiva e foi mais longe em sua fantasia, identificando a "Bonequinha" como filha da "Obla Bruxa". Karla e Maya juntas, a partir da provocação da educadora, criaram a ideia da bruxa boa. No faz de conta, a bruxa é boa e por isso tem nome e filha. Outra ação criadora mais rica se deu quando Karla criou uma voz específica para o seu personagem.

\section{$4^{\circ}$ EPISÓDIO: Tentativa de composição da história novamente sugerida pela educadora}

No teatrinho se encontravam M. Ely com o fantoche do "Bicho Cárie", que ela passou a nomear de "Jacaré", Yana com a "Obla Bruxa", Karla com a "Bonequinha" (identificada como filha da 
“Obla Bruxa”) e Maya com o "Feitiço". A educadora busca ampliar ainda mais as tentativas das crianças na composição de um enredo e sugere novamente que elas "contem uma história". KARLA: - "Oi! Oi! Oi! Tá tudo bem? Quem é você?"

MAYA: - "Você é quem?"

M.ELY: - "Tá tudo bem?"

YANA: - "Você é quem?"

Educadora: - "Meu nome é Luana. Qual o nome de vocês?"

KARLA: - "Sou uma bruxinha". (Com o fantoche da "Bonequinha", filha da "Obla Bruxa").

M. ELY: - "Sou o "Jacaré".

YANA: - "Eu sou o Jacaré, igual ao sapo". (Com o fantoche da "Obla Bruxa").

Educadora: - "Você é o sapo?"

MÁRIO: - "Eu, eu, tia... eu sou a "Bruxa". (Com o fantoche do "Feitiço").

FAUSTO: - "Ah, Mário é o Feitiço".

KARLA: - "Eu vou contar uma história".

Yana sai do teatrinho, senta-se no chão e fica explorando o fantoche da "Obla Bruxa", manipulando-o. Karla fica contando a história, criando voz própria para o personagem ${ }^{9}$. Maya interage com Karla, falando frases com a voz modificada também. Em seguida, M. Ely faz o mesmo. As três crianças balançam os fantoches no teatrinho e induzem a educadora a participar da brincadeira, convidando-a a se apresentar. Agora todas as crianças criam vozes modificadas para os fantoches. Por fim, M. Ely fala: "Vamos trocar?"

\section{Discussão do $4^{\circ}$ episódio}

Arranjo espacial: a educadora, que tinha como propósito, desde o início, levar o grupo a compor uma história, novamente sugeriu às crianças que estavam com os fantoches para irem para trás do teatrinho e criar essa história. Elas acataram o pedido, mas 
acabaram por ficar brincando com os fantoches, nomeando-os. Para as crianças, nomear os personagens era a brincadeira e não compor uma história com início, meio e fim.

Composição da história: nesse episódio, as crianças iniciaram a brincadeira transgredindo a proposta da educadora, incluindo-a como personagem da trama e fazendo com que os fantoches (personagens da história) interagissem com ela. As crianças fizeram perguntas e a educadora respondeu, interagindo com os personagens sem perceber que havia sido enredada pelas crianças. Os parceiros mais velhos confirmaram as denominações dadas aos fantoches e os mais novos imitaram os mais velhos. Yana disse que a "Obla Bruxa" era um sapo como o "Jacaré" e Maya disse que o "Feitiço" era, naquele momento, a "Bruxa".

Ação criadora: ao final, Karla disse: "Eu vou contar uma história". E, modificando sua voz (tornando-a mais fina), criou frases para a personagem. Após observá-la, M. Ely e Maya fizeram o mesmo. Por fim, as três crianças balançaram os fantoches no teatrinho e falaram frases com suas vozes modificadas, criando vozes para todos os fantoches. Infelizmente, as falas com as vozes modificadas ficaram mais finas e baixas, o que dificultou entender o texto criado. Na verdade, o texto não era o mais importante, mas sim o faz de conta desenvolvido pelas crianças com as nomeações dos fantoches, sua renomeação e a modificação das vozes.

\section{$5^{\circ}$ EPISÓDIO: Tentativa de composição da história pelas crianças focais}

A educadora quer a composição de uma história, e, por isso, segue tentando criar estratégias para que sua proposta se realize. Sugere, novamente, que as quatro crianças focais contem uma história com os fantoches.

YANA: - "Esse é o "Lobo Mau". (Mostra o fantoche do "Bicho Cárie").

MAYA: - "Oi, tia". 
Educadora: - "Conta uma historinha".

MÁRIO: - "Era uma vez uma Bruxa". (O teatrinho começa a cair). MÁRIO: - "A Bruxa vai comer vocês".

Gina começa a cantar a música do sapo Cururu. Yana canta a música do "Jacaré", (anteriormente cantada pelos parceiros mais experientes). Todos cantam a música do Jacaré. Yana canta e pula balançando o fantoche do "Lobo Mau". A educadora insiste que elas ampliem a história. As crianças conversam entre si, e Yana fica pulando e cantando. Como o teatrinho estava caindo repetida vezes, a educadora o retira e Mário faz uma expressão de não ter gostado daquilo.

YANA: - "Era uma vez uma boneca". (Aponta para o "Bicho Cárie", dizendo que era o "Lobo").

GINA: - "Eu sou o Lobo".

MAYA: - "Eu sou o Lobão".

YANA: "Eu sou o Lobinho".

GINA: - "Eu sou o Lobo mau".

MAYA: - "Eu sou o Lobão".

YANA: - "Eu sou o Lobin". (Fica brincando de pular e trocar de cadeira).

Maya imita o que Yana faz.

YANA: - "Aqui o pé dele". (Mostra os pés do fantoche).

MAYA: - "Olha aqui o pé dele". (Mostra a mão do "Bicho Cárie").

YANA: - "Isso não é pé dele".

MAYA: - "Ele tá sem pé". (Retira o fantoche da mão).

Gina, que agora participa da brincadeira, balança o fantoche do menino sem o encaixar na mão, na direção de Mário, que bate no fantoche e diz para parar. Em seguida, abraça o fantoche da bruxa que está com ele e sorri.

GINA: - "Só tô mostrando... Você tá brincando com ela, com a Bruxa, né?"

MÁRIO: - "Não!"

YANA: - "Não quero mais".

GINA: - "A Bruxa é a mãe".

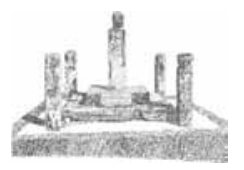


MAYA: - "Era uma vez..."

MÁRIO: - "Olha eu". (Coloca a "Bruxa" no ombro).

GINA: - "Olha eu, hein". (Coloca o fantoche do menino no ombro).

MAYA: - "Olha eu, olha, Mário". (Pula).

YANA: - "Olha eu". (Pula imitando Maya).

Maya imita Yana, pulando novamente e caindo sentada ao chão.

Mário imita a ação de Maya e Gina imita Mário. Então todos começam a pular e a dizer: "Ruy, olha eu". E os membros do grupo, coletivamente, imitam uns aos outros.

\section{Discussão do $5^{\circ}$ episódio}

Arranjo espacial: a educadora continuou insistindo para que as crianças contassem uma história atrás do teatrinho, porém esse equipamento atrapalhou a composição da história, o que a fez retirá-lo, reorganizando o cenário com um círculo de cadeiras. Ela solicitou que as crianças mais novas se sentassem e contassem uma história com os fantoches. Mário não gostou dessa nova arrumação espacial.

Liberdade de expressão verbal e corporal: apesar de a educadora ter insistido para que as crianças criassem uma história, ela permitiu que as expressões verbais e corporais se desenvolvessem. Para as crianças, esta era a brincadeira: criar e recriar personagens, trocar fantoches, fazer vozes para representá-los e incluir canções já conhecidas, inspiradas nas novas nomeações dadas aos fantoches. Pela idade, elas têm necessidade de mexer o corpo e criar diálogos curtos, coerentes, que proporcionem desenvoltura verbal, corporal e cognitiva. O elo do faz de conta se deu via imitação, que se apresentou em vários momentos nos episódios. Por exemplo, uma das crinças cantou, outra também cantou e ampliou o cantar; uma pulou e outra pulou incrementando movimentos. Uma criança disse: "Sou o Lobo"; outra a imitou e ampliou: "Sou o Lobão"; outra disse: "Sou o Lobinho". Assim umas foram transformando as ações das outras, acrescentando 
elementos próprios a cada imitação. Um fator que nos chama a atenção é a frase utilizada por eles, "Olha eu", que descreve um mecanismo utilizado para perceber o outro e o meio, atuar neles e ser percebido por eles. A palavra "olha" demonstra que eles observam (e muito) o tempo inteiro, e "eu" indica que realizam o observado e pedem a confirmação de que estão sendo vistos e que o que fazem está "correto".

Assim, expressam que estar com parceiros mais velhos potencializa, de fato, seu desenvolvimento e amplia a aquisição de conhecimento dos menores. No faz de conta, geralmente, o parceiro mais velho realiza ações que os mais novos ainda não fazem, porém, ao interagirem maiores e menores, em situações variadas, torna-se possível o olhar, o observar e, mais adiante, na brincadeira, o realizar, o executar, o fazer de modo ressignificado.

\section{Síntese interpretativa dos episódios interativos}

Antes da apresentação dos fantoches, a educadora estimulou a curiosidade do grupo de crianças, perguntando o que havia no "saco surpresa". Uma delas logo soltou a imaginação lhe respondendo que existiam dinossauros. A educadora seguiu provocando-os e os convidou a mexer nos fantoches.

Após o primeiro contato, um menino retirou do saco o boneco do "Bicho Cárie", nomeando-o "Lobo". Encaixou o mesmo na mão, demonstrando familiaridade com a atividade de contar histórias com fantoches. As crianças os manusearam bastante, correndo com eles, nomeando-os, abraçando-os, mostrando-os aos colegas e à educadora. Negociaram entre si a posse dos fantoches, mas não iniciaram espontaneamente a produção de nenhum enredo. Talvez por serem pequenos, precisassem do incentivo do adulto (educadora) que os ajudou a ampliar a imaginação. A educadora sugeriu que as crianças que estavam com os fantoches fossem para o teatrinho e narrassem uma história. No início, as crianças acharam interessante e fizeram o que a educadora sugeriu.

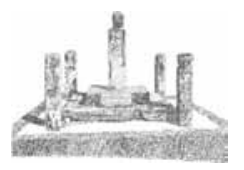


Percebemos que elas, apesar de iniciarem um diálogo com os colegas da plateia, não se sentiram bem no espaço de contação de histórias (teatrinho). A princípio, ficaram sentadas e, depois, para melhor atuarem, de pé. As falas, os gestos e os movimentos das crianças indicaram proposições inovadoras e foram valorizadas pela educadora. Ela interagiu com os personagens criados pelas crianças e as encorajou a apresentarem uma história criada por elas. Porém, ressaltamos a curiosidade e o interesse das crianças na exploração dos fantoches, pois logo iniciaram negociações e as trocas dos mesmos.

Durante o primeiro momento de tentativa de montar uma história, uma das crianças focais, Yana, se destacou. Inicialmente, ela observou um colega mais velho, Fausto, com o fantoche denominado por ele "Júlio" e imitou os movimentos que o colega fez com o "boneco". Apesar de o fantoche de Yana não estar encaixado como o de Fausto, ela tentou interagir com o colega usando o brinquedo, porém ele não respondeu à brincadeira.

Um fato muito importante foi perceber que as crianças não precisam estar no espaço do teatrinho para criarem histórias ou fazerem com que os fantoches interajam. Muitas vezes, elas preferem brincar com os fantoches, com o colega ao lado ou com a educadora, a criar uma história para a plateia. Repetidas vezes, elas romperam com o real e viveram ações criativas, o que foi proveitoso e incentivado pela educadora, que, apesar de insistir na criação de uma história para ser contada no teatrinho, deixouas livres em suas formas próprias de expressão. Em relação a essa discussão, Vygotsky (1998a) acrescenta que

o teatro das crianças, quando pretende reproduzir diretamente as formas do teatro adulto, constitui uma ocupação pouco recomendável para as crianças. Começar com um texto literário, memorizar palavras estranhas como fazem os atores profissionais, palavras que nem sempre correspondem à compreensão e aos sentimentos das crianças, interrompe a criação infantil e converte 
as crianças em repetidores de frases de outros obrigados pelo roteiro. Por isso se aproximam mais da compreensão infantil as obras compostas pelas próprias crianças ou improvisadas por elas no curso de sua criação. [...] Estas obras resultam, sem dúvida, mais imperfeitas e menos literárias que as preparadas e escritas por autores adultos, mas possuem a enorme vantagem de terem sido criadas pelas próprias crianças. Não se deve esquecer que a lei básica da criação artística infantil consiste em que seu valor não reside no resultado, no produto da criação, mas no processo de criação em si (VYGOTSKY, 1998a, p. 87-88).

Nesse caso, houve iniciativa e liberdade de não se prender a um foco específico ou a um modo único para a contação de histórias por parte das crianças, pois naturalmente no ambiente de sala de atividade, brincando com os fantoches, como mostram os episódios, elas interagem com os objetos e com as pessoas presentes, de forma a criarem diferentes situações de faz de conta. Como é esperado nessa faixa etária (três e quatro anos), as crianças interagiram usando gestos, movimentos, sentidos, entonações de voz, enfim, um conjunto variado de elementos corporais que lhes possibilitaram agir e interagir com desenvoltura, especialmente com os colegas.

Dessa forma, ficou nítida a importância das interações de crianças com níveis de desenvolvimento diferenciado para potencializar as trocas e a criação de zonas de desenvolvimento proximal. Cabe ao educador, assim, estar sempre atento, observando e pesquisando os mais diversos sinais que a criança produz ao romper com o real para, paradoxalmente, apropriar-se criativamente da realidade.

\section{Visão prospectiva}

Nos últimos anos, há grandes avanços em relação à elaboração de documentos oficiais voltados para a infância. Entre eles,

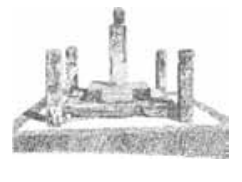


destacam-se as Diretrizes Curriculares Nacionais (BRASIL, 2000) e os Parâmetros Nacionais de Qualidade para a Educação Infantil, volumes 1 e 2 (BRASIL, 2006). Ambos são direcionados para a educação infantil e privilegiam o lúdico como elemento norteador. Esses documentos enfatizam, primordialmente, em seus modelos curriculares, a importância do brincar, ressaltando sua contribuição para o desenvolvimento e a aprendizagem da criança. Igualmente, buscam mostrar que é por meio da brincadeira que a criança vive a realidade, interage com o meio e com os outros, construindo significados e os ressignificando. Ao imaginar e criar, a criança desenvolve o pensamento, a afetividade, a linguagem, enfim, todo o seu ser.

Na contramão desses documentos, não é raro encontrar, em muitas realidades de educação infantil, ainda hoje, o predomínio e a valorização de práticas escolarizantes cuja ênfase está no decorar e copiar números e letras. Tais práticas apoiam-se em posturas pedagógicas autoritárias e conservadoras que menosprezam a ludicidade no processo de desenvolvimento e aprendizagem.

Por essa razão, neste artigo, procurou-se argumentar em favor de uma prática em educação infantil que explore as possibilidades e a riqueza das interações de crianças de diferentes idades, contribuindo para a criação de zonas de desenvolvimento proximal. Para isso, é necessário que se priorize fundamentalmente a criança como protagonista de seu desenvolvimento, garantindolhe a liberdade de ação nas brincadeiras por intermédio da criação de enredos, escolha de personagens, construção de cenários etc. Apostamos numa prática pedagógica comprometida com o "criançar", isto é, que valorize as necessidades e as potencialidades da criança e que contribua para que ela viva a infância com dignidade e respeito.

De acordo com a perspectiva de Vygotsky, existe um lugar do outro social, da cultura e da história na constituição das capacidades criadoras e criativas dos sujeitos tornando-os pessoas humanas. Esse novo olhar que se faz e se refaz na reflexão 
pedagógica constitui e permite ao educador romper com os conceitos cristalizados e orientados pelo racionalismo das práticas educativas na educação infantil. Consequentemente, requer um educador que se inquiete com o mundo como dado, pronto e acabado, que busque caminhos e respostas, além de transitar na multiplicidade que a diferença exige.

Nessa perspectiva dialética, encontramos a práxis da creche institucional em estudo, que, por meio de uma proposta pedagógica pautada na abordagem histórico-cultural, desenvolve um trabalho voltado para o cuidado e a educação integrados, procurando respeitar a criança e seu processo de aprendizado e desenvolvimento. Ao organizar agrupamentos de crianças com idades diferentes, a creche cria contextos que potencializam esses processos e leva em consideração não apenas o que já foi desenvolvido pela criança, mas, sobretudo, o que ainda está por vir, promovendo o surgimento de níveis de desenvolvimentos potenciais, ou seja, a zona de desenvolvimento proximal.

Nossa intenção foi a de destacar o papel do parceiro mais velho nas brincadeiras de faz de conta como elemento catalisador do desenvolvimento infantil, bem como a de ressaltar a ação criativa e autônoma da criança, transformando e ressignificando as propostas iniciais trazidas pelos educadores.

Procuramos enfatizar a importância da interação criançacriança e compreender o quanto as crianças mais velhas têm formas elaboradas de interação com as mais novas, o que, cuidadosamente mediado por educadores atentos, pode provocar ações recíprocas e coordenadas entre os parceiros, evidenciando jogos de papéis e contra papéis. Dessa forma, buscamos explicitar o quanto a dinâmica de organização de turmas com crianças de idades diferentes potencializa o processo de aprendizado e o desenvolvimento de todas as crianças envolvidas.

Pensamos prospectivamente a ação educativa nas unidades de educação infantil e seu papel no desenvolvimento e na aprendizagem. Por isso, acreditamos que a organização de 
agrupamentos com idades heterogêneas se constitui numa proposta pedagógica coerente com o ideário de uma educação de qualidade, no qual a diferença seja vista como aspecto fundamental para a riqueza.

Por fim, esperamos que este trabalho sirva de instrumento de reflexão sobre o fazer pedagógico nas unidades de educação infantil para educadores, coordenadores e diretores, favorecendo a criação de práticas inovadoras que deem visibilidade às competências e habilidades das crianças. 


\section{Referências}

AQUINO, L. M. L. de. Ordenamento legal para educação infantil e desafios para os gestores municipais. In: VASCONCELLOS, T. (Org). Reflexões sobre infância e cultura. Niterói: EDUFF, 2008. p. 185-206.

. Do direito à obrigação. Pátio - Educação Infantil, n. 22, p. 44-46, jan./mar. 2010.

BROUGERE, G. Brinquedo e Cultura. São Paulo: Summus, 2000. . Brinquedo e Cultura. Revisão técnica e versão brasileira adaptada por WAJSKOP, G. 5. ed. São Paulo: Cortez, 2004. - (Coleção Questões da Nossa Época, v. 43).

BRASIL. Diretrizes Curriculares Nacionais para Educação Infantil Resolução n. 5, de 17 de dezembro de 2009. Brasília: CNE, SEB, 2009.

- Parâmetros Nacionais de Qualidade para a Educação

Infantil / Ministério da Educação. v. 1 e 2. Brasília: Secretaria de Educação Básica, 2006.

. Congresso Nacional. Lei de Diretrizes e Bases da Educação Nacional. Lei n. 9.394/96, de 20 de dezembro de 1996. Estabelece as Diretrizes e Base da Educação Nacional. Diário Oficial da União, Brasília, DF, 23 de dezembro de 1996.

. Constituição (1988). Constituição da República

Federativa do Brasil. Brasília: Senado Federal, 1988.

FREIRE, D. B. S. Interação entre crianças de diferentes idades. Rio de Janeiro, 1990. 
GÓES, M. C. R. de. A abordagem microgenética na matriz histórico-cultural: uma perspectiva para o estudo da constituição da subjetividade. Cadernos CEDES, Campinas, $\mathrm{n}$. 50, p. 90-95, 2000.

KISHIMOTO, T. M. (Org.). Jogo, brinquedo, brincadeira e a educação. 8. ed. São Paulo: Cortez.

NASCIMENTO, C. de S. Processos criativos na brincadeira de faz de conta: uma análise microgenética de episódios interativos. 2005. 150 f. Dissertação (Mestrado em Educação) - PPGE/ Universidade Federal Fluminense, Rio de Janeiro, 2005.

OLIVEIRA, Z. M. Creches: crianças, faz de conta e cia. Petrópolis: Vozes, 1992.

. Reinações infantis: um olhar sobre as interações de crianças em creches. 1995. 200 f. Tese de livre-docência não publicada - FFCLRP / Universidade de São Paulo, Ribeirão Preto, 1995.

ROCHA, M. S. P. M. L. Não brinco mais: a (des) construção do brincar no cotidiano educacional. Rio Grande do Sul: Unijuí, 2000.

TAILLE, Y. de La; OLIVEIRA, M. K. de; DANTAS, H. Piaget, Vygotsky e Wallon: Teorias psicogenéticas em discussão. São Paulo: Summus, 1992.

VASCONCELLOS, V. M. R. de. Zona de desenvolvimento proximal: a brincadeira na creche. In: FREITAS, M. T. de A. (Org.). Vygotsky um século depois. Juiz de Fora: EDUFJF, 1998. . Uma visão prospectiva de desenvolvimento em que o presente está sempre recriando o passado. In: COLINVAUX, 
D.; LEITE, L. B.; DELL'AGLIO, D. D. (Org.). Psicologias de desenvolvimento: reflexões e práticas atuais. São Paulo: Casa do Psicólogo, 2006.

VYGOTSKY, L. S. A formação social da mente: o desenvolvimento dos processos superiores. São Paulo: Martins Fontes, 1998a.

. La Imaginación y el arte em la infância. Madrid:

Ediciones Akal, 1998b . 


\title{
Playing with older peers and child development at the child care center
}

\begin{abstract}
In this paper we analyze children's actions and narratives during pretend play as well as the teacher's role in allowing or not for their creativity in the context of a dramatization task. Participants included a teacher from a public child care center in interaction with four 3 and four 4 years old children. The teacher gives to the group of children a black plastic bag and four puppets each measuring about three feet. The puppets were: a "charming" witch, a girl, a boy and an animal. The teacher asked them to create a drama situation with the others using the puppets. Our aim was to investigate to what extent the young children were able to identify and assume the oldest child's point of view. All episodes were recorded in video and we conducted a microgenetic analysis of the interactive episodes. We found that the teacher same times have difficulty in engaging in pretend play in the school context situation, and also in accepting that imaginary situation in other ways of playing different that what she had planned before. On the other hand, the teacher did mediate children's interactions and creative productions.
\end{abstract}

Keywords: child care center; pretending play; zone of proximal development. 